\title{
FRIEDEL-CRAFTS ALKYLATION OF ANISOLE AND BENZYL BROMIDE USING ZIF-8 AS AN EFFICIENT CATALYST
}

\author{
Phan Thanh Son Nam ${ }^{(1)}$, Le Khac Anh Ky ${ }^{(1)}$, Nguyen Thi Hong Nhung ${ }^{(2)}$ \\ (1) University of Technology, VNU-HCM \\ (2) Nong Lam University of HCM city \\ (Manuscript Received on May $13^{\text {rd }}$ 2010, Manuscript Revised October 12 $2^{\text {nd }} 2011$ )
}

ABSTRACT: A highly porous zeolite imidazolate frameworks (ZIF-8) was synthesized from the reaction of zinc nitrate hexahydrate and 2-methylimidazole by a solvothermal method in DMF. The ZIF-8 was characterized using several techniques including X-ray powder diffraction (XRD), scanning electron microscope (SEM), transmission electron microscope (TEM), thermogravimetric analysis (TGA), Fourier transform infrared (FT-IR), atomic absorption spectrophotometry (AAS), and nitrogen physisorption measurements. Highly crystalline porous ZIF-8 was achieved with Langmuir surface areas of more than $1700 \mathrm{~m}^{2} / \mathrm{g}$ being observed. The ZIF-8 could be effectively used as a solid acid catalyst for the Friedel-Crafts alkylation reaction between anisole and benzyl bromide with no contribution from homogeneous catalysis of active acid species leaching into reaction solution.

Keywords: ZIF-8, XRD, Friedel-Crafts alkylation reaction.

\section{INTRODUCTION}

Metal-organic frameworks (MOFs) are currently receiving significant attention as promising materials for applications involving catalysis, separation, gas storage, and molecular recognition [1-4]. MOFs are extended porous structures composed of transition metal ions (or clusters) that are linked by organic bridges [5]. Zeolite imidazolate frameworks (ZIFs), being classified as a new subclass of MOFs, have emerged as a novel type of highly porous materials, combining advantages from both zeolites and conventional MOFs [6,7]. Compared to conventionally used microporous and mesoporous inorganic materials, these metal-organic structures have the potential for more flexible rational design, through control of the architecture and functionalization of the pores $[8,9]$.

Friedel-Crafts acylation of aromatic compounds with acid chlorides is an important process in both petroleum and chemical industries. These reaction are traditionally catalyzed by more than stoichiometric amounts of anhydrous strong Lewis acids such as $\mathrm{AlCl}_{3}, \mathrm{TiCl}_{3}, \mathrm{FeCl}_{3}$, or $\mathrm{SnCl}_{4}$ [10]. This method is limited by high amounts, toxicity and corrosion of the catalysts, generation of a large amount of waste, and difficult purification of the desired products [11]. Moreover, these catalysts are highly moisture sensitive and hence demand moisture-free solvents, reactants and anhydrous catalysts, and also a dry atmosphere for their handling [12]. In this paper, we wish to report for the first time in Viet Nam, to our best knowledge, the utilization of a highly porous zeolite imidazolate frameworks (ZIF-8) as an efficient heterogeneous catalyst for liquid phase Friedel-Crafts alkylation reactions.

\section{EXPERIMENTAL}

\subsection{Materials and instrumentation}

Chemicals were purchased from Sigma-Aldrich and Merck, and used as received without further 
TẠP CHÍ PHÁT TRIỂN KH\&CN, TẬP 14, SỐ K4 - 2011

purification unless otherwise noted. Fourier transform infrared (FT-IR) spectra were obtained on a Bruker TENSOR37 instrument with samples being dispersed on potassium bromide pallets. Scanning electron microscope (SEM) studies were performed on a JSM 740. Transmission electron microscope (TEM) studies were performed using a JEOL JEM 1400, in which samples were dispersed on holey carbon grids for TEM observation. . Elemental analysis with atomic absorption spectrophotometry (AAS) was performed on an AA-6800 Shimadzu.

A Netzsch Thermoanalyzer STA 409 was used for simultaneous thermal analysis combining thermogravimetric analysis (TGA) and differential thermal analysis (DTA) with a heating rate of $10^{\circ} \mathrm{C} /$ min under a nitrogen atmosphere. X-ray powder diffraction (XRD) patterns were recorded using $\mathrm{Cu}$ $\mathrm{K} \alpha$ radiation source on a D8 Advance Bruker powder diffractometer. Nitrogen physisorption measurements were conducted using a Quantachrome Nova 2200e, in which samples were pretreated by heating under vacuum at $150{ }^{\circ} \mathrm{C}$ for $3 \mathrm{~h}$.

Gas chromatographic (GC) analyses were performed using a Shimadzu GC 17-A equipped with a flame ionization detector (FID) and an DB-5 column (length $=30 \mathrm{~m}$, inner diameter $=0.25 \mathrm{~mm}$, and film thickness $=0.25 \mu \mathrm{m})$. The temperature program for GC analysis heated samples from 60 to $140{ }^{\circ} \mathrm{C}$ at $10{ }^{\circ} \mathrm{C} / \mathrm{min}$ and held them at $140{ }^{\circ} \mathrm{C}$ for 1 min; then heated them from 140 to $300{ }^{\circ} \mathrm{C}$ at 50 ${ }^{\circ} \mathrm{C} / \mathrm{min}$ and held them at $300{ }^{\circ} \mathrm{C}$ for $3 \mathrm{~min}$. Inlet and detector temperatures were set constant at $300{ }^{\circ} \mathrm{C}$. $n$ Hexadecane was used as an internal standard to calculate reaction conversions. GC-MS analyses were performed using a Hewlett Packard GC-MS 5972 with a RTX-5MS column (length $=30 \mathrm{~m}$, inner diameter $=0.25 \mathrm{~mm}$, and film thickness $=0.5 \mu \mathrm{m}$ ).

\subsection{Synthesis of ZIF-8}

In a typical preparation, a solid mixture of zinc nitrate hexahydrate $\left(\mathrm{Zn}\left(\mathrm{NO}_{3}\right)_{2} \cdot 6 \mathrm{H}_{2} \mathrm{O}\right) \quad(1.88 \mathrm{~g}$, $6.33 \mathrm{mmol}$ ) and 2-methylimidazole (H-MeIM) (0.43g, $5.82 \mathrm{mmol})$ was dissolved in $130 \mathrm{ml}$ of $N, N^{\prime}-$ dimethylformamide (DMF) in a $10 \times 20 \mathrm{ml}$ vials. The vial was tightly capped and heated at a rate of 5 ${ }^{\circ} \mathrm{C} / \mathrm{min}$ to $140{ }^{\circ} \mathrm{C}$ in a programmable oven and held at this temperature for $24 \mathrm{~h}$, then cooled at a rate of 0.4 ${ }^{\circ} \mathrm{C} / \mathrm{min}$ to room temperature. After removal of mother liquor from the mixture, chloroform $(20 \mathrm{ml})$ was added to the vial. Colorless polyhedral crystals were collected from the upper chloroform layer, washed with DMF $(3 \times 15 \mathrm{ml})$ for 3 days. After that, the DMF was exchanged by dichloromethane (DCM) (3 $\mathrm{x} 15 \mathrm{ml}$ ) for 3 days. The residual solvents were removed under vacuum at $200{ }^{\circ} \mathrm{C}$ for $6 \mathrm{~h}$, yielding $0.26 \mathrm{~g}$ of white polyhedral crystals ( $23 \%$ based on 2methylimidazole).

\subsection{Catalysis studies}

In a typical reaction, a mixture of anisole (1.94 $\mathrm{ml}, 17.94 \mathrm{mmol})$, benzyl bromide $(0.75 \mathrm{ml}, 4.38$ mmol) and $n$-dodecane $(0.35 \mathrm{ml})$ as an internal standard was added into a $50 \mathrm{~mL}$ flask containing the ZIF-8 catalyst. The catalyst concentration was calculated with respect to the zinc / benzyl bromide molar ratio. The resulting mixture was stirred at the desired temperature for $6 \mathrm{~h}$. Reaction conversion was monitored by withdrawing aliquots from the reaction mixture at different time intervals, quenching with an aqueous $\mathrm{Na}_{2} \mathrm{CO}_{3}$ solution $(1 \%, 1 \mathrm{ml})$. The organic components were extracted into diethyl ether $(3 \mathrm{x} 1$ ml) which was then dried over anhydrous $\mathrm{Na}_{2} \mathrm{SO}_{4}$, and analyzed by GC with reference to $n$-dodecane. The product identity was further confirmed by GCMS.

\section{RESULTS AND DISCUSSION}




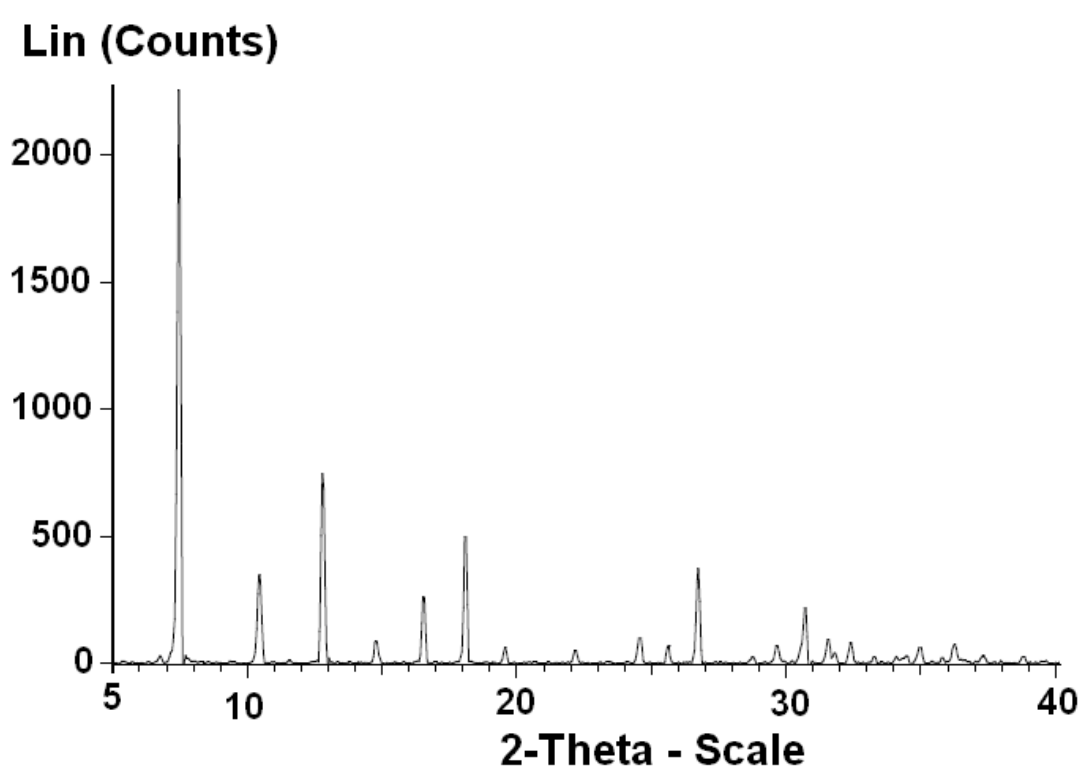

Figure 1. X-ray powder diffractogram of the ZIF-8

The ZIF-8 was synthesized using zinc nitrate hexahydrate and 2-methylimidazole by a solvothermal method in DMF, according to a literature procedure [13]. The ZIF-8 was then characterized using a variety of different techniques. Elemental analysis with AAS indicated a zinc loading of $4.17 \mathrm{mmol} / \mathrm{g}$. A very sharp peak below $10^{\circ}$ (with $2 \theta$ of 7.2) was observed on the XRD diffractogram of the ZIF-8, indicating that a highly crystalline material

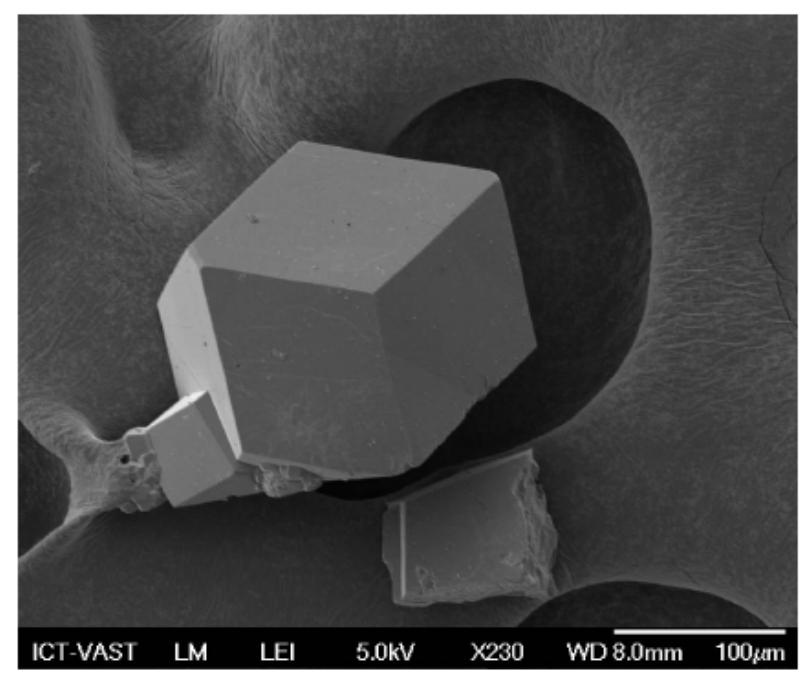

was achieved (Figure 1). Furthermore, the XRD patterns of the ZIF- 8 exhibited a better crystallinity as compared to that of silica-based materials such as SBA-15, SBA-16 and MCM-41 where broader peaks were normally observed on their diffactograms [14]. Indeed, high crystallinity is always expected when synthesizing MOF-based materials. The overall XRD patterns of the ZIF-8 were in good agreement with the literature $[13,15]$.

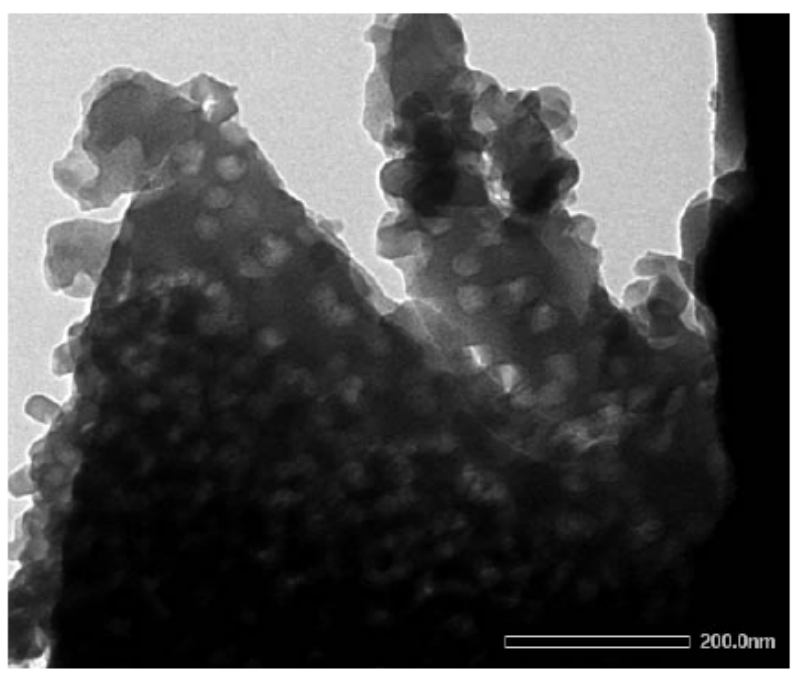

Figure 2. SEM (left), and TEM (right) micrographs of the ZIF-8 
The SEM micrograph showed that well-shaped, high quality polyhedral crystals with crystal sizes ranging between approximately 100 and $200 \mu \mathrm{m}$ were observed (Figure 2). The SEM images, together with the XRD patterns showed that the ZIF-8 was highly crystalline. As expected, the TEM observation revealed that the as-synthesized ZIF- 8 possessed a highly porous structure (Figure 2, right), which was different from that of conventionally used microporous and mesoporous inorganic materials. Thermal degradation investigations of solid materials are necessary as many applications depend on their thermal stability. In this work, the TGA results showed that the ZIF- 8 was stable up to over $400{ }^{\circ} \mathrm{C}$ in air, ensuring the applicability of the ZIF-8 across a wide temperature range (Figure 3).

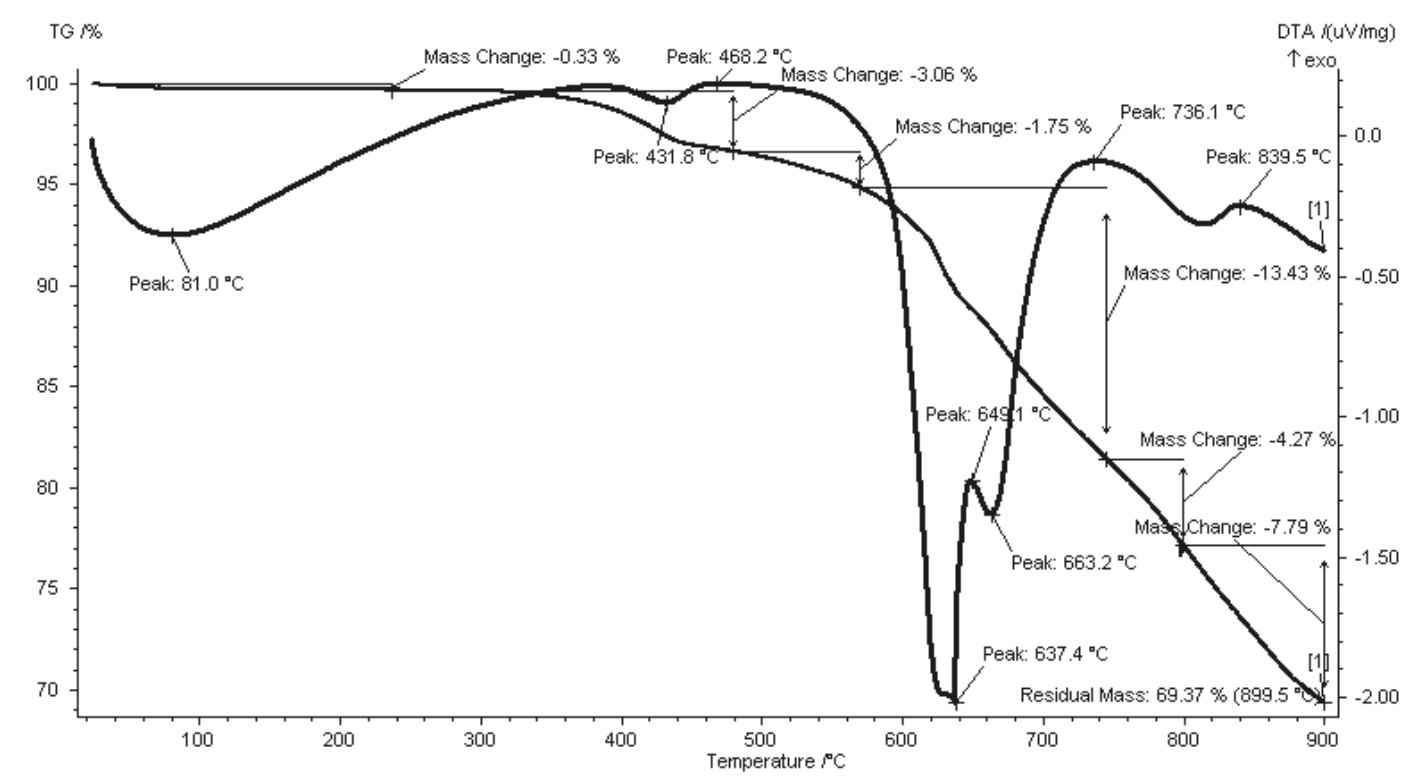

Figure 3. TGA result of the ZIF-8

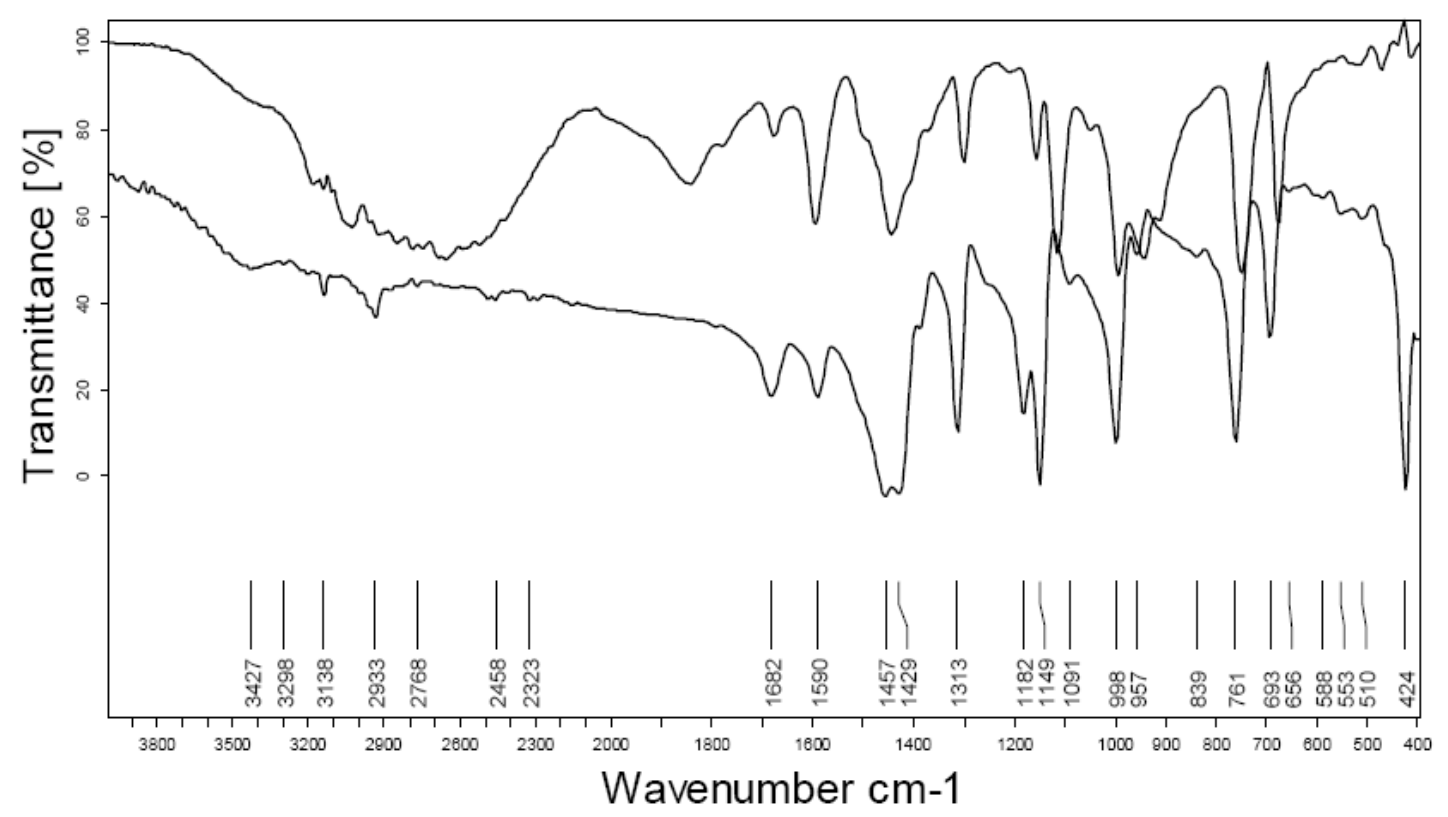

Figure 4. FT-IR spectra of the 2-methylimidazole linker (above) and the ZIF-8 (below) 
FT-IR spectra of the ZIF-8 exhibited a significant difference as compared to that of 2-methylimidazole (Figure 3, above). In the FT-IR spectra of 2methylimidazole, a strong and broad band, extending over the frequency range $3400-2200 \mathrm{~cm}^{-1}$ with the maximum at approximately $2600 \mathrm{~cm}^{-1}$ was observed, indicating the presence of the $\mathrm{N}-\mathrm{H}$... $\mathrm{N}$ hydrogen bond. A relatively narrow band of medium intensity was also found at $1843 \mathrm{~cm}^{-1}$, which was identified as the resonance between the N-H...N bending "out of plane" and the N-H stretching vibrations [16]. The disappearance of these absorption bands in the FT-IR spectra of the ZIF-8 (Figure 4, below) indicated that the 2-methylimidazole linkers were fully deprotonated.

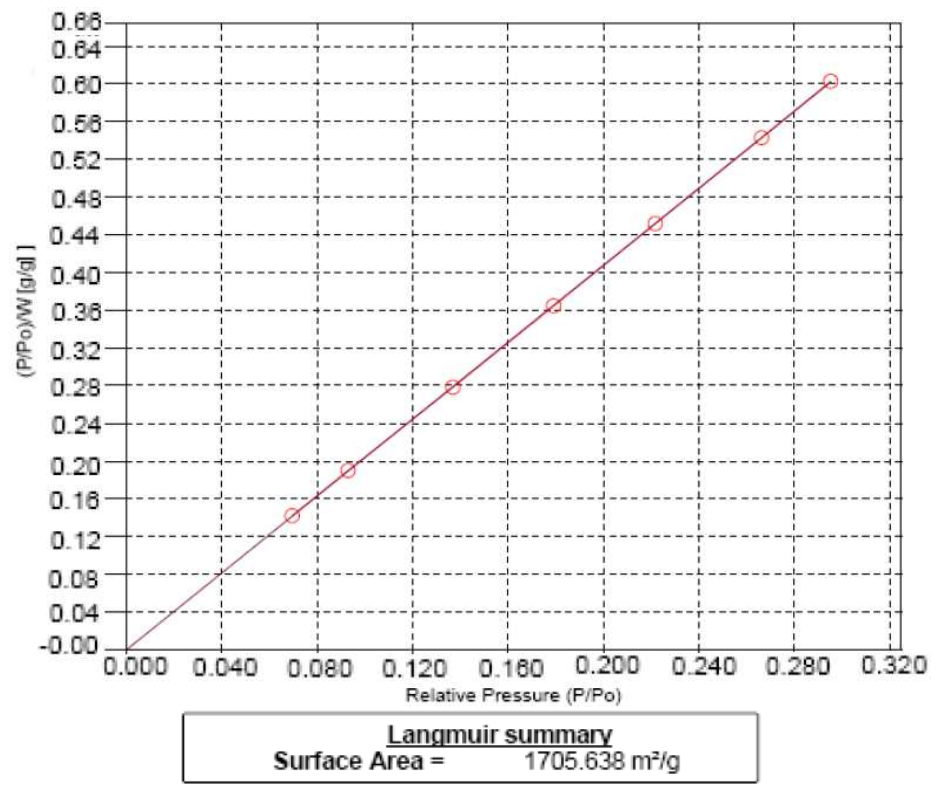

Figure 5. Langmuir surface areas of the ZIF-8

As mentioned earlier, MOF-based materials are currently receiving significant attention as promising materials for applications involving catalysis, separation, and gas storage because of their exceptionally high adsorption surface areas [1-5]. The claim for the highest surface areas of a disordered structure was for activated carbon which was around $2000 \mathrm{~m}^{2} / \mathrm{g}$, while the largest surface areas of ordered structures such as zeolites or silicas was observed at around $1000 \mathrm{~m}^{2} / \mathrm{g}$ [1]. With the invention of MOFs, the surface areas of crystalline porous materials could be significantly improved. Interesting, it was found that the ZIF-8 synthesized in this research could afford Langmuir surface areas of up to $1705 \mathrm{~m}^{2} / \mathrm{g}$ (Figure 5). Indeed, several ZIF-8 samples with surface areas ranging from $1300 \mathrm{~m}^{2} / \mathrm{g}$ to $1810 \mathrm{~m}^{2} / \mathrm{g}$ were previously synthesized using solvothermal method $[6,13]$. 

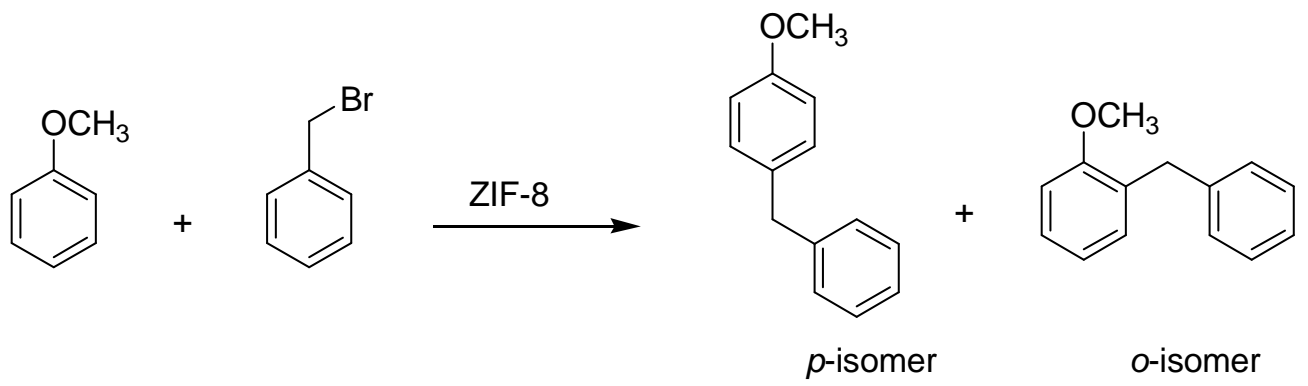

Scheme 1. The Friedel-Crafts alkylation reaction between anisole and benzyl bromide using the ZIF-8 catalyst.

The ZIF-8 was assessed for its activity as a solid catalyst in the Friedel-Crafts alkylation of anisole with benzyl bromide to form $p$-benzylanisole as the principal product and $o$-benzylanisole as the byproduct (Scheme 1). Effect of temperature on reaction conversion and selectivity was studied in the range of $80-100{ }^{\circ} \mathrm{C}$, using $5 \mathrm{~mol} \% \mathrm{ZIF}-8$ catalyst and benzyl bromide molar ratio of $2: 1$. Quantitative conversion of benzyl bromide was achieved after $3 \mathrm{~h}$ at the reaction temperature of $100{ }^{\circ} \mathrm{C}$ without the need for an inert atmosphere, and a selectivity to $p$ -

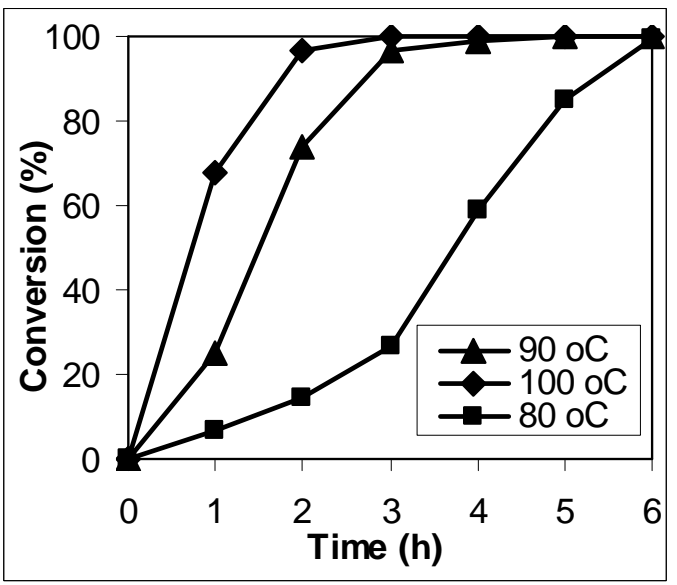

Figure 6. Effect of temperature on reaction conversion benzylanisole of $75 \%$ was detected in the product mixture. As expected, decreasing the temperature resulted in a drop in reaction rate, with conversions of $97 \%$ and $27 \%$ being observed after $3 \mathrm{~h}$ at $90{ }^{\circ} \mathrm{C}$ and $80{ }^{\circ} \mathrm{C}$, respectively (Figure 6). However, the alkylation reaction could go to completion after $6 \mathrm{~h}$ in all cases. The selectivity of the $p$-isomer to the $o$ isomer remained almost unchanged at different temperature, being around $75 \%$ of $p$-isomer (Figure 7).

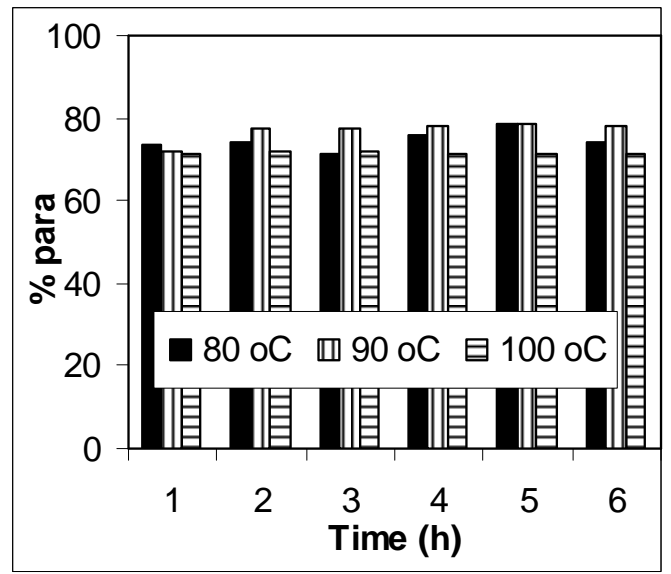

Figure 7. Effect of temperature on reaction selectivity 


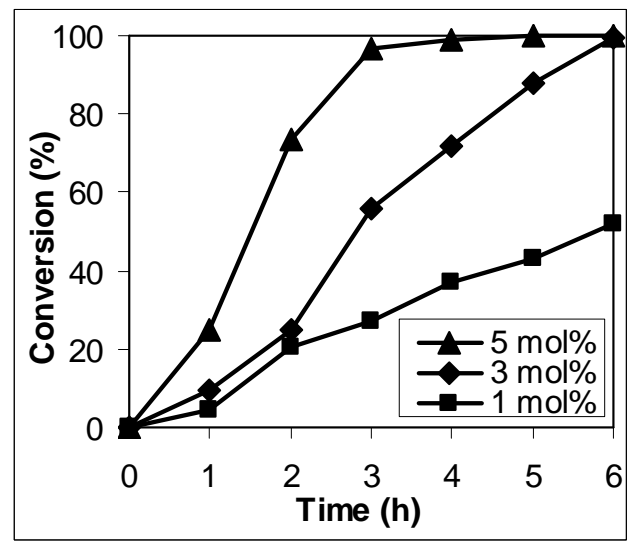

Figure 8. Effect of catalyst concentration on reaction conversion

With the result in hand, we then decided to investigate the effect of catalyst concentration on reaction conversion. It was previously reported that Friedel-Crafts alkylation reactions required a large amount of anhydrous $\mathrm{AlCl}_{3}$ catalyst, which could not be reused because of its instability [10-12]. Replacement of environmentally unacceptable anhydrous $\mathrm{AlCl}_{3}$ with solid acids has been shown to effectively reduce the amount of catalyst for FriedelCrafts alkylation reactions, in which the catalyst concentrations could vary from less than $0.1 \mathrm{~mol} \%$ to more than $10 \mathrm{~mol} \%$, depending on the nature of the catalyst as well as the substrate [17-19]. The catalyst concentration, with respect to the zinc content in the

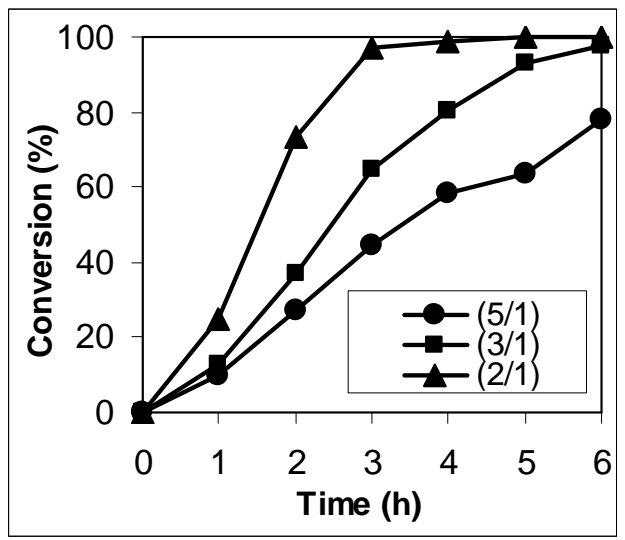

Figure 10. Effect of molar ratio on reaction conversion

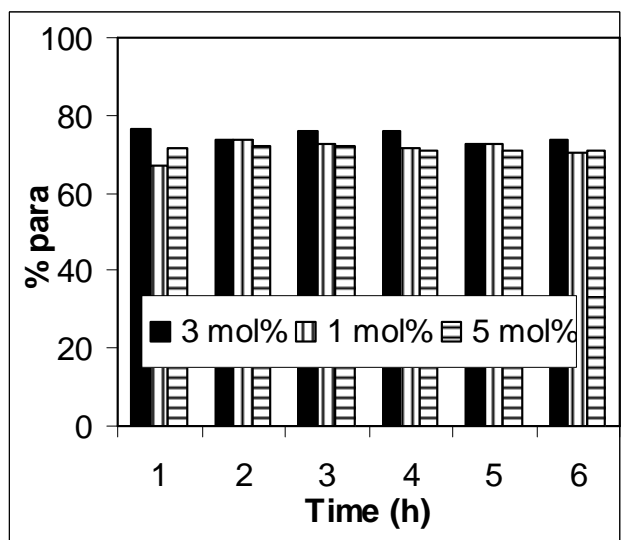

Figure 9. Effect of catalyst concentration on reaction selectivity

ZIF-8, was studied in the range of $1-5 \mathrm{~mol} \%$ relative to benzyl bromide at a reaction temperature of $90{ }^{\circ} \mathrm{C}$. It was found that quantitative conversion of benzyl bromide was achieved after $5 \mathrm{~h}$ using $5 \mathrm{~mol} \%$ ZIF-8 catalyst (Figure 8). As expected, decreasing the catalyst loading to $3 \mathrm{~mol} \%$ resulted in a drop in reaction rate. However the reaction could afford a conversion of more than $99 \%$ at $3 \mathrm{~mol} \%$ catalyst after $6 \mathrm{~h}$. The catalyst concentrations used in this study were therefore comparable to the literature. As expected, it was found that the selectivity of the $p$ isomer remained almost unchanged, being approximately $75 \%$ in the catalyst concentration range of $1-5 \mathrm{~mol} \%$ (Figure 9 ).

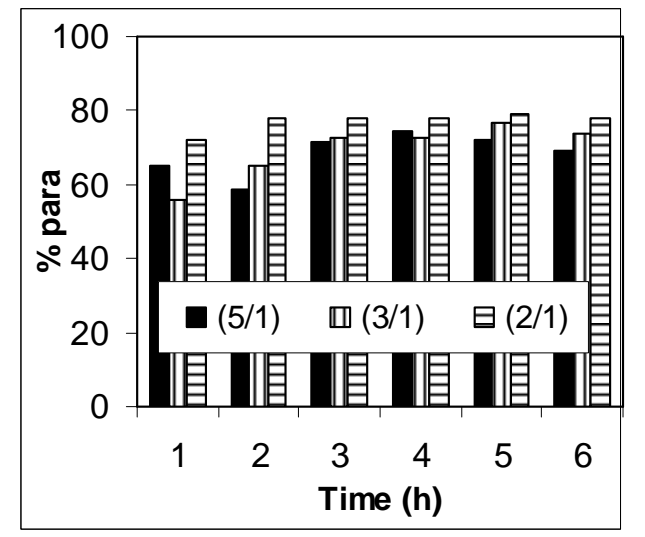

Figure 11. Effect of molar ratio on reaction selectivity 
It should be noted that Friedel-Crafts alkylation reactions are normally carried out under solvent-free conditions. A large excess of aromatic hydrocarbon is usually required in order to achieve high selectivity toward monosubstitution. The excess aromatic hydrocarbon also acts as a reaction medium for the alkylation process. It was previously reported that the Friedel-Crafts benzylations of toluene or benzene using solid acid catalysts required a toluene : benzyl halide or benzene : benzyl halide molar ratio of up to $13: 1[17,20]$. Effect of reactant ratio was therefore investigated, having carried out the reaction at 5 mol\% catalyst at $90{ }^{\circ} \mathrm{C}$, using the benzyl bromide molar ratio of $2: 1,3: 1$ and $5: 1$, respectively. It was found that the reaction rate was decreased if the toluene : benzyl bromide molar ratio increased from 2:1 to 5:1 (Figure 10). In a heterogeneous reaction, mass transfer limitation would normally have a significant effect on the reaction rate. Therefore, increasing the amount of the solvent could lead to a drop in reaction rate. From experimental points of view, it should be noted that using toluene : benzyl bromide molar ratio of less than $2: 1$ could cause difficulty in stirring the reaction mixture containing the solid catalyst. As expected, the selectivity of the $p$-isomer to the $o$-isomer remained almost unchanged at different molar ratio, being around $75 \%$ of $p$ isomer (Figure 11).

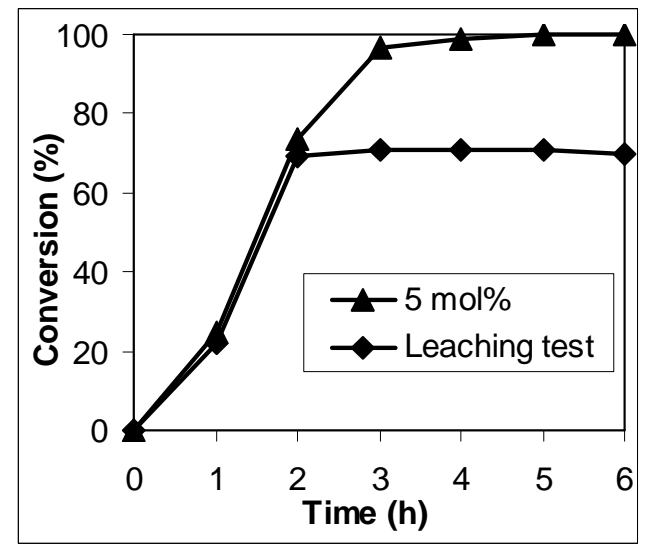

Figure 12. Leaching test indicated no contribution from homogeneous catalysis

When using a solid catalyst, a crucial issue is the possibility that some of active sites could migrate from the solid support to the liquid phase and that these leached species could become responsible for a significant part of the catalytic activity. In order to determine if leaching was a problem for the FriedelCrafts alkylation reaction using the ZIF-8 catalyst, an experiment was performed to estimate the contribution of leached active species to the catalytic activity by performing a simple centrifugation during the course of the reaction to remove the solid catalyst. If the catalytic reaction continued this would indicate that the active species was leached acid rather than the solid ZIF-8 catalyst. The organic phase was separated from the solid catalyst after $2 \mathrm{~h}$ reaction time by simple centrifugation, having used 5 mol\% fresh ZIF-8 catalyst. The reaction solution was transferred to a new reactor vessel, and stirred for an additional $4 \mathrm{~h}$ at $90{ }^{\circ} \mathrm{C}$ with aliquots being sampled at different time intervals, and analyzed by GC. The data from GC determinations gave quantitative information about residual, catalytically active acid in solution. Within experimental error, no further reaction was observed, proving there to be no contribution from leached active species and 
conversion only being possible in the presence of the solid ZIF-8 catalyst (Figure 12).

\section{CONCLUSION}

In summary, a highly porous zeolite imidazolate frameworks (ZIF-8) was synthesized from the reaction of zinc nitrate hexahydrate and 2methylimidazole by a solvothermal method in DMF. The ZIF-8 were characterized using several techniques including XRD, SEM, TEM, TGA, FTIR, AAS and nitrogen physisorption measurements, and the analysis results were in good agreement with the literature. Highly crystalline porous ZIF-8 was achieved with Langmuir surface areas of more than $1700 \mathrm{~m}^{2} / \mathrm{g}$. The ZIF-8 could be effectively used as a solid catalyst for the Friedel-Crafts alkylation reaction between toluene and benzyl bromide. It was apparent that the ZIF-8 catalyst exhibited advantages over conventional Lewis acid catalysts such as $\mathrm{AlCl}_{3}$, $\mathrm{FeCl}_{3}$, and $\mathrm{ZnCl}_{2}$ in the Friedel-Crafts alkylation reaction. Our results here demonstrated the feasibility of employing MOF-based materials as heterogeneous catalysts for several organic transformations. Further exploration on applications of MOF-based materials in catalysis appears warranted, and is the focus of ongoing investigation.

\title{
NGHIÊN CÚU SỬ DỤNG ZIF-8 LÀM XÚC TÁC CHO PHẢN ỨNG ALKYL HÓA THEO FRIEDEL-CRAFTS CỦA ANISOLE VỚI BENZYL BROMIDE
}

\author{
Phan Thanh Sơn Nam, Lê Khắc Anh Kỳ, Nguyễn Thị Hồng Nhung \\ Trường Đại học Bách Khoa, ĐHQG-HCM
}

TÓM TÄT: Vật liệu khung hũu co - kim loại với cấu trúc tương tụ nhu zeolite (ZIF-8) đã được tổng hợp theo phương pháp kết hợp nhiệt độ và dung môi tù phản úng giũa zinc nitrate hexahydrate và 2-methylimidazole. Xúc tác được phân tích bằng nhũng phương pháp nhu nhiễu xạ tia X (XRD), hiển vi điện tủ quét (SEM), hiển vi điện tủ truyền qua (TEM), phân tích nhiệt trọng luợng (TGA), phổ hồng ngoại (FT-IR), quang phổ hấp thu nguyên tủ (AAS) và đo bề mặt riêng Langmuir. ZIF-8 được tổng hợp với bề mặt riêng Langmuir trên $1700 \mathrm{~m}^{2} / g$. Xúc tác ZIF-8 thể hiện hoạt tính tốt trong phản ứng alkyl hóa theo Friedel-Crafts giũa anisole với benzyl bromide mà không cần môi trường khi tro cũng như các hóa chất khan nước. Kết quả nghiên cứu còn cho thấy phản ứng alkyl hóa trên xúc tác ZIF-8 xảy ra dị thể mà không có đóng góp của phần xúc tác hòa tan vào dung dịch phản úng.

\section{REFERENCES}

[1] H. K. Chae, D. Y. Siberio-Pe'rez, J. Kim, Y. Go, M. Eddaoudi, A. J. Matzger, M. O'Keeffe, O. M. Yaghi, A route to high surface area, porosity and inclusion of large molecules in crystals Nature, 427, 523 (2004).

[2] D. J. Tranchemontagne, Z. Ni, M. O'keeffe, O. M. Yaghi, Reticular chemistry of metalorganic poluhedra, Angew, Chem, Int, Ed., 47, 5136 (2008). 
[3] S.S. Kaye, A. Dailly, O.M. Yaghi, J.R. Long, Impact of preparation and handling on the hydrogen storage properties of $\mathrm{Zn}_{4} \mathrm{O}$ (1,4-benzenedicarboxylate $)_{3} \quad$ (MOF-5), J. Am, Chem. Soc., 129, 14176 (2007).

[4] H. Furukawa, M. Miller, O.M. Yaghi, J. Mater, Independent verification of the saturation hydrogen uptake in MOF-177 and establishment of a benchmark for hydrogen adsorption in metal-organic frameworks, Chem., 17, 3197 (2007).

[5] O. M. Yaghi, M. O'Keeffe, N. Ockwig, H. K. Chae, M. Eddaoudi, J. Kim, Reticular synthesis and the design of new materials, Nature, 423, 705 (2003).

[6] Phan, C. J. Doonan, F. J. Uribe-Romo, C. B. Knobler, M. O'Keeffe, O. M. Yaghi, Synthesis, structure, and carbon dioxide capture properties of zeolitic imidazolate frameworks, Acc. Chem. Res. 43, 58 (2009)

[7] S. R. Venna, M. A. Carreon, Highly permeable zeolite imidazolate Framework-8 membranes for $\mathrm{CO}_{2} / \mathrm{CH}_{4}$ separation, J. Am. Chem. Soc. 132, 76 (2010).

[8] H. Li, M. Eddaoudi, M. O'Keeffe, O. M. Yaghi, Design and synthesis of an exceptionally stable and highly porous metal-organic framework, Nature 402, 276 (1999).

[9] J. L. C. Rowsell, O. M. Yaghi, Metalorganic frameworks: a new class of porous materials, Micropor. Mesopor. Mater, 73, 3 (2004).

[10]D. O. Jang, K. S. Moon, D. H. Choa, J. G. Kim, Highly selective catalytic FriedelCrafts acylation and sulfonylation of activated aromatic compounds using indium metal, Tetrahedron Lett., 47, 6063 (2006).

[11]R. G. Noronha, A. C. Fernandes, C. C. Romão, $\mathrm{MoO}_{2} \mathrm{Cl}_{2}$ as a novel catalyst for Friedel-Crafts acylation and sulfonylation, Tetrahedron Lett., 50, 1407 (2009).

[12] K. Mantri, K. Komura, Y. Kubota, Y. Sugi, Friedel-Crafts alkylation of aromatics with benzyl alcohols catalyzed by rare earth metal triflates supported on MCM-41 mesoporous silica, J. Mol. Catal. A 236, 168 (2005).

[13] K. S. Park, Z. Ni, A. P. Côté, J. Y. Choi, R. D. Huang, F. J. Uribe-Romo, H. K. Chae, M. O'Keeffe, O. M. Yaghi, Exceptional chemical and thermal stability of zeolitic imidazolate frameworks, Proc. Natl. Acad. Sci. USA 103, 10186 (2006).

[14] D. Zhao, Q. Huo, J. Feng, B. F. Chmelka, G. D. Stucky, Nonionic triblock and star diblock copolymer and oligomeric surfactant syntheses of highly ordered, hydrothermally stable, mesoporous silica structures, J. Am. Chem. Soc., 120, 6024 (1998).

[15]G. Lu, J. T. Hupp, Metal-organic frameworks as sensors: a ZIF-8 based Fabry-Pelrot device as a selective sensor for chemical vapors and gases, J. Am. Chem. Soc., 132, 7832 (2010).

[16] B. Hachuła, M. Nowak, J. Kusz, Crystal and molecular structure analysis of 2methylimidazole, J Chem Crystallogr, 40, 201 (2010).

[17] M. J. Gracia, E. Losada, R. Luque, J. M. Campelo, D. Luna, J. M. Marinas, A. A. Romero, Activity of Gallium and Aluminum 
SBA-15 materials in the Friedel-Crafts alkylation of toluene with benzyl chloride and benzyl alcohol, Appl. Catal. A, 349, 148 (2008).

[18]S. Sebti, R. Tahir, R. Nazih, S. Boulaajaj, Comparison of different Lewis acid supported on hydroxyapatite as new catalyst of Friedel-Crafts alkylation, Appl. Catal. A, 218, 25 (2001).
[19] O. S. Ahmeda, D. K. Dutta, Friedels-Crafts benzylation of benzene using $\mathrm{Zn}$ and $\mathrm{Cd}$ ions exchanged clay composites, J. Mol. Catal. A, 229, 227 (2005).

[20] V. R. Choudhary, R. Jha, V. S. Narkhede, In-Mg-hydrotalcite anionic clay as catalyst or catalyst precusor for Friedel-Crafts type benzylation reactions, J. Mol. Catal. A, 239, $76(2005)$ 